\title{
A TARIFAÇÃO DO DANO MORAL NA JUSTIÇA DO TRABALHO: UMA ANÁLISE DA (IN)CONSTITUCIONALIDADE DIANTE DOS PARÂMETROS FIXADOS PELA REFORMA TRABALHISTA
}

\author{
THE RATIONALE OF MORAL DAMAGE IN THE WORK JUSTICE: AN \\ ANALYSIS OF (UN)CONSTITUTIONALITY BEFORE THE PARAMETERS \\ SET BY THE LABOR REFORM
}

\author{
José Claudio Monteiro de Brito Filho \\ Centro Universitário do Estado do Pará - Cesupa - (Belém, PA, Brasil) \\ Sarah Gabay Pereira \\ Centro Universitário do Estado do Pará - Cesupa - (Belém, PA, Brasil)
}

Recebimento: 31 maio 2019

Aceitação: 15 set. 2019

\begin{abstract}
Como citar este artigo / How to cite this article (informe a data atual de acesso / inform the current date of access):
BRITO FILHO, José Claudio Monteiro de; PEREIRA, Sarah Gabay. A tarifação do dano moral na Justiça do Trabalho: uma análise da (in)constitucionalidade diante dos parâmetros fixados pela reforma trabalhista. Revista da Faculdade de Direito UFPR, Curitiba, PR, Brasil, v. 65, n. 1, p. 39-58, jan./abr. 2020. ISSN 2236-7284. Disponível em: $<$ https://revistas.ufpr.br/direito/article/view/67193>. Acesso $\quad$ em: $30 \quad$ abr. $2020 . \quad$ DOI: http://dx.doi.org/10.5380/rfdufpr.v65i1.67193.
\end{abstract}

\section{RESUMO}

Neste estudo pretende-se analisar, por meio do método hipotético-dedutivo, a inovação da reforma trabalhista na tarifação do dano moral. O objetivo é verificar se o art. 223-G, § 1, da CLT é constitucional, a partir da análise de sua observância ou não ao princípio da igualdade, sendo a hipótese de pesquisa a de que ele, além de inconstitucional, é insatisfatório na reparação do dano extrapatrimonial na prática trabalhista. O artigo pretende responder se o art. 223-G, § 1, da CLT encontra-se dentro dos ditames constitucionais, apontando suas consequências práticas. Para responder ao problema a que se propõe, o desenvolvimento da pesquisa será dividido em três seções: inicialmente será feita uma análise do instituto do dano moral e sua aplicação na seara trabalhista; na seção seguinte serão apresentadas as redações dos artigos introduzidos pela reforma trabalhista e o antigo texto da Medida Provisória 808/2017; por fim, será objeto de discussão a parcial inconstitucionalidade da tarifação do dano moral trabalhista.

\section{PALAVRAS-CHAVE}

Reforma trabalhista. Tarifação do dano moral. (In)constitucionalidade. Princípio da igualdade.

\section{ABSTRACT}

This study aims to analyze, through the hypothetico-deductive method, the innovation of the labor reform on the rationale of moral damages. The objective is to verify if the art. 223-G, $\S 1$, of the Brazilian Consolidation of Labor Laws (CLT) is constitutional, based on the analysis of its compliance or not with the equality principle, and the research hypothesis is that, besides being unconstitutional, it is unsatisfactory in repairing extra-patrimonial damage in labor practice. This article intends to answer if the art. 223-G, $\S 1$, of the CLT is within the constitutional dictates, pointing 
out its practical consequences. To respond the problem it proposes, the development of the research will be divided into three sections: first an analysis will be made of the institute of moral damage and its application in the labor matters; the following section will present the wording of the articles introduced by the labor reform and the old text of Provisional Measure 808/2017; finally, the partial unconstitutionality of the moral damage compensation will be discussed.

\section{KEYWORDS}

Labor reform. Rationale of moral damage. (Un)constitutionality. Equality Principle.

\section{INTRODUÇÃo}

Recentemente, foi aprovada a reforma trabalhista, e, com ela, diversas modificações foram vivenciadas no mundo do trabalho. A Lei 13.467/17, que entrou em vigor em 11 de novembro de 2017, já fazendo efeito, agora, há mais de dois anos, será tema do presente artigo, com especial enfoque para a reparação do dano extrapatrimonial.

Cumpre ressaltar que o presente texto não tem o escopo de valorar pronta e superficialmente, de forma finalística, geral ou abstrata, se a reforma foi benéfica ou maléfica; afinal, todas as reformas tendem a abarcar aspectos positivos e negativos.

É que, ao lado de uma evidente precarização do trabalho, observada na forma como foram regulamentados o trabalho intermitente e a terceirização, houve avanços nítidos em matéria de relações coletivas de trabalho, como o fim da contribuição sindical e da discussão a respeito da ultratividade das normas convencionais coletivas. Assim, nem haveria como fazer uma indicação peremptória a respeito de ser a reforma boa ou má, salvo analisando-se cada um de seus aspectos.

Dessa forma, optou-se por abordar, neste texto - até pelo espaço reduzido de um artigo científico, que se presta a discussões bem delimitadas -, tão somente a modificação quanto à fixação do dano moral trabalhista, por ser agora expressamente prevista a sua forma na CLT, com vistas a observar quais foram as principais alterações havidas em relação a esta matéria, bem como, adiantase, discutir como este dispositivo, atualmente, consolida injustiças.

O problema da pesquisa consiste em responder se a atual previsão do art. 223-G, § 1, da CLT é constitucional e se ela se demonstra satisfatória na devida reparação de possíveis danos ocorridos a trabalhadores.

Diante do explicitado, e pela correspondência entre problema e objetivo, o objetivo geral do presente trabalho é analisar se a inovação da redação do art. 223-G, § 1, da CLT é dotada de constitucionalidade, além de apontar seus efeitos práticos na reparação dos danos aos trabalhadores, a fim de que se possa responder ao problema de pesquisa deste trabalho. 
Ressalta-se que o tema-alvo delimitado é de fundamental relevância para o Direito do Trabalho, tendo em vista que, diante de qualquer reforma do texto legal, princípios constitucionalmente estabelecidos podem ser violados, reduzindo, de alguma perspectiva, direito devidamente assegurado nos moldes do Estado Democrático de Direito.

Ademais, cumpre salientar que, em razão da recente implementação da reforma trabalhista, vários questionamentos são comuns e plausíveis, importantes para o debate no contexto acadêmico, assim como nas cortes, as quais devem estar atentas para possíveis inconstitucionalidades na reforma de normas legais.

O método de pesquisa utilizado neste trabalho será o hipotético-dedutivo, abarcando, no Direito do Trabalho, doutrinadores como Maurício Godinho Delgado (2017) e sua obra "Curso do direito do trabalho”, na sua 16a edição, Carlos Henrique Bezerra Leite (2017) e o livro “Curso de direito do trabalho”, em sua 8a edição, Henrique Correia (2018) e “Direito do trabalho para concursos de analista do TRT, TST e MPU” e Irany Ferrari e Melchíades Rodrigues Martins (2005) e “Dano moral: múltiplos aspectos nas relações de trabalho”. Sobre direito previdenciário, Hugo Goes (2018) e seu texto "Manual de direito previdenciário: teoria e questões”. Quando ao direito civil, as obras de Pablo Stolze Gagliano e Rodolfo Pamplona Filho (2013) e de Caio Mário da Silva Pereira (2018), respectivamente, “Novo curso de direito civil” e "Responsabilidade Civil”, além dos artigos de Enoque Ribeiro dos Santos (2017) (“O dano extrapatrimonial na Lei n. 13.467/2007, da reforma trabalhista”) e Cássio Casagrande (2017) (“A reforma trabalhista e a inconstitucionalidade da tarifação do dano moral com base no salário do empregado”). Ademais, salienta-se que esta é uma pesquisa bibliográfica, constituindo-se em um estudo teórico-normativo sobre a Lei 13.467/2017.

O artigo está dividido em quatro seções. Após esta introdução, inicialmente, será estabelecido o conceito de dano extrapatrimonial, relacionando-o à justiça laboral. Em seguida, será retratada a evolução do artigo legal que versa sobre o dano moral trabalhista, incluindo o texto da Medida Provisória 808/2017 e sua perda de efeitos, o que garantiu a permanência do texto aprovado originariamente pelo Legislativo. Ao fim, abordar-se-á o vigente artigo relativo ao dano extrapatrimonial e os argumentos de sua (in)constitucionalidade, atrelada às suas consequências práticas na reparação ao trabalhador, respondendo ao problema de pesquisa.

\section{O INSTITUTO DO DANO MORAL E A SEARA TRABALHISTA}

O instituto do dano extrapatrimonial, no plano normativo, advém do Código Civil, encontrando respaldo nos art. 927 e seguintes. Na perspectiva civilista, segundo Gagliano e Pamplona 
Filho (2013, p. 105), o conceito de dano moral consiste na lesão não pecuniária, sendo aquela que nem mesmo é “comercialmente redutível a dinheiro”. Acrescentam, ainda, os autores que é o tipo de lesão que atinge a esfera personalíssima, capaz de causar ao lesionado violação de direitos de personalidade, tais quais o direito à honra e à imagem.

Entende-se, portanto, por dano moral, aquele causado pela violação de direitos intangíveis factualmente, de ordem que ferem aquilo que é impalpável, não reproduzido no mundo físico. Assim, o dano extrapatrimonial atinge a esfera do íntimo de cada indivíduo, de incabível reprodução pecuniária.

A violação dos direitos de personalidade pode ser direta ou indireta, conforme preceituam, também, os referidos autores.

Caracteriza-se o dano moral direto quando há um bem específico violado, ao passo que o indireto é constituído de forma reflexa a um dano previamente havido. Para melhor compreensão do segundo, Gagliano e Pamplona Filho (2013, p. 117) exemplificam com o furto hipotético de um objeto que possui valor afetivo, situação em que só haveria dano extrapatrimonial em razão de dano anterior, qual seja, o furto.

A redação do Código Civil sofreu influência axiológica do texto constitucional, tendo em vista que o último preceitua, no Art. 5, incisos V e X, que:

\footnotetext{
V-É assegurado o direito de resposta, proporcional ao agravo, além da indenização por dano material, moral ou à imagem;

$[\ldots]$

X- São invioláveis a intimidade, a vida privada, a honra e a imagem das pessoas, assegurado o direito a indenização pelo dano material ou moral decorrente de sua violação (BRASIL, 1988)
}

O texto constitucional, portanto, prevê amparo ao indivíduo que se entender lesado em seu direito intangível, constituindo-lhe o direito de ação, e consequente reparação, caso seja constatada pelo juízo a violação de direito fundamental.

É interessante salientar que, diferentemente do dano patrimonial, inexiste a possibilidade de retornar ao status quo ante ao dano. É inviável, portanto, reconfigurar o momento anterior à lesão. Nesse diapasão, em razão da incapacidade de restituir novamente o direito lesado, para não desamparar aqueles que sofreram violações aos direitos de personalidade, o Código Civil previu a conversão da reparação em moeda, pois, sempre que configurado o ato lesivo, surge com ele o direito de reparação, que será patrimonial.

O que não poderia haver seria não ocorrer reparação, pois, havendo lesão a direito subjetivo, impõe-se alguma forma de recomposição deste direito. 
Em síntese, nesse tipo de dano, diante da incapacidade do direito de garantir a devolução do estado anterior ao dano, as violações extrapatrimoniais podem ser reparadas patrimonialmente.

Essa aferição patrimonial é realizada por meio da liquidação do dano sofrido, pautada em determinação de acordo com o caso concreto, por meio do valor da causa e da observação pelo juiz das circunstâncias que agravam ou diminuem o quantum indenizatório.

Assevera Caio Mário da Silva Pereira (2018, p. 250) que:

[...] algumas decisões do STJ têm aplicado o chamado método bifásico no arbitramento do dano moral, que, na determinação do quantum debeatur, parte numa primeira fase do patamar de indenização normalmente atribuído àquele grupo de casos, para, já na segunda fase, ajustar a indenização com base nas circunstâncias do caso concreto e no interesse jurídico lesado.

No âmbito da esfera trabalhista foi acolhido o conceito de dano extrapatrimonial de forma a inseri-lo dentro do contexto das práticas laborais. É de se observar que o cotidiano do trabalhador pode propiciar uma série de violações à integridade moral, adequando-se o instituto às demandas trabalhistas.

A propósito do dano extrapatrimonial na esfera trabalhista, até então regulada a partir da legislação comum, optou o legislador ordinário por um disciplinamento específico e exclusivo, pois o artigo 223-A da CLT, introduzido pela Lei n. 13.467/2017 prescreve claramente que para a reparação desse tipo de dano somente deverão ser utilizados os dispositivos próprios agora previstos na CLT.

A esse respeito, Oliveira (2018, p. 231) indica que o legislador registrou, de forma clara e expressa, que não cabe a aplicação subsidiária do Direito Civil, pois, entende esse autor, a ideia foi o de estabelecer uma indenização em modo próprio, e que, entende ele, será parcial.

Voltando a uma apreciação mais genérica, conforme comentam Irany Ferrari e Melchíades Rodrigues Martins (2005, p. 15):

[...] a matéria tem hoje proteção no mundo jurídico, principalmente na seara das relações laborais, em face das modalidades de dano moral encontradas no seu meio, como o assédio moral, assédio sexual, revistas em empregados, monitoramentos eletrônicos e outras formas que vão surgindo na medida em que avança o processo da globalização e das relações de trabalho.

Além das citadas hipóteses, indicadas pelos autores, cumpre destacar que o dano moral trabalhista é amplo, abrangendo diversas outras situações relativas ao contrato de trabalho - tais como a ausência de assinatura da CTPS, atos discriminatórios, dano moral decorrente de acidente de trabalho -, diante das vastas possibilidades de enquadramento na realidade dos trabalhadores. 
A esse respeito, cumpre observar que, pela reforma, conforme artigos 223-C e 223-D, foram enumerados, aparentemente de forma exaustiva, as hipóteses de dano moral. Como eles não atingem, nem em parte, a multiplicidade de situações em que pode ocorrer dano moral, Oliveira (2018, p. 234) defende que a enumeração deve ser tida como exemplificativa. Assim também se entende neste trabalho.

É imperioso lembrar que o dano moral na Justiça do Trabalho não se limita ou não se restringe à responsabilidade e à condenação, tão somente, do sujeito empregador. É que o tomador dos serviços, tendo seu direito de personalidade lesado, faz jus ao pedido de dano moral decorrente de atitude de empregado, podendo pleitear o reconhecimento deste dano e a consequente condenação do obreiro.

O melhor exemplo para caracterizar o dano moral praticado pelo empregado é aquele em que o direito de imagem da empresa é maculado por atitudes do trabalhador. Nesse caso, é viável a condenação deste em pecúnia, caracterizando a via de mão dupla quanto ao dano extrapatrimonial nas relações laborais.

Dando seguimento à conceituação do dano moral na seara trabalhista, é mister citar a exemplificação do instituto por Delgado (2017, p. 703), uma vez que este afirma ser ato lesivo:

\begin{abstract}
[...] por exemplo, a indenização em face de discriminação racial promovida pela empresa contra o obreiro, a par da indenização por indevido uso da imagem do trabalhador nas atividades empresariais. Em um segundo plano, há as indenizações relativas a danos à segurança e saúde físicas e morais do empregado no contexto do cumprimento contratual (lesões acidentárias). Desponta aqui a possibilidade de distintas indenizações, todas englobadas nos efeitos conexos do contrato de trabalho: por dano material, por dano moral e, finalmente, até mesmo por dano estético.
\end{abstract}

Comumente, há dano moral trabalhista quando o juiz, no caso concreto, observa que determinadas práticas, quer sejam do empregado ou do empregador, proporcionam uma lesão frontal aos direitos de personalidade, quais sejam, a honra, a imagem, a intimidade e a vida privada, tanto do obreiro, como da parte mais forte da relação de trabalho.

O dano moral, apesar de faticamente incontestável em certas ocasiões, demanda um esforço de motivação do julgador. Diferentemente do dano material, que em muitos casos é de mais fácil aferição, o dano extrapatrimonial, pela sua própria natureza, exige que o dever de reparar seja subjetivo por diversos ângulos.

Em certas ocasiões, o dano moral é de fato devido; no entanto, sua natureza imprecisa e subjetiva remonta a um cenário de inexatidão, que reforça a imperfeição da plena aplicação do instituto. 
A liquidação do dano moral torna-se um exercício complexo e inovador para o juiz, tendo em vista que "desponta novo desafio judicante, qual seja o de fixar o montante financeiro compensatório pertinente (indenização pelo dano ocorrido)” (DELGADO, 2017, p. 712).

Ainda referenciando o autor, a quantificação do dano deve estar associada aos princípios da equidade, evitando que casos distintos sejam tratados sob uma mesma ótica, da imparcialidade e da sensatez.

Somado a isso, o valor atingido deve-se mostrar razoável ao dano sofrido, sem que se imponha, à parte que o efetuou, ônus desproporcional:

\begin{abstract}
Não pode a indenização ser inexpressiva, a ponto de não cumprir qualquer de seus objetivos reparadores e pedagógicos, desprestigiando, ademais, a ordem jurídica constitucional e legal e o próprio Judiciário. Não pode também ser, ao revés, exorbitante, a ponto de provocar enriquecimento sem causa do beneficiado e desarrazoado dispêndio ao ofensor. Nos dois casos, seja o de valores inexpressivos, excessivamente módicos, seja o de valores exorbitantes, estratosféricos, o montante indenizatório deixa de observar os princípios cardeais da proporcionalidade e da razoabilidade, que regem o presente tema (DELGADO, 2017, p. 716, grifo do autor).
\end{abstract}

Como alhures mencionado, portanto, o valor alcançado no processo não deve se mostrar desarrazoado diante do dano ínfimo ocasionado, valendo a mesma lógica para os danos desmedidos, de vulto, com indenizações irrisórias. A propósito, essa lição de Delgado, acima transcrita, vai servir para a conclusão que será manifestada adiante, embora não seja motivadora de idêntica conclusão, para outros autores.

Apesar da dificuldade de estabelecer um parâmetro para os valores que possam ser tidos como em descompasso com o dano reconhecido, entender-se-á como desproporcional ou irrisória a quantia estipulada que, sem questionamentos, aparentar ser excessiva ou reduzida demais para as circunstâncias do caso concreto, com a análise sendo feita sob a perspectiva de comum consentimento em um padrão médio de estipulação.

A esse respeito, é importante observar que, tratando-se de dano extrapatrimonial, não há como pretender reparação que se possa dizer, objetivamente, integral, pela subjetividade que sempre estará presente e, por isso, há a convicção de que, na generalidade dos casos, trabalhar-se-á com a ideia de um padrão médio, a refletir a ideia de proporcionalidade.

Feitas essas considerações, agora que houve a devida compreensão sobre o dano moral relativo ao trabalhador, convém iniciar o debate mais específico a respeito do texto celetista e da reforma trabalhista. 


\section{O DANO MORAL, A REFORMA TRABALHISTA E A MEDIDA PROVISÓRIA No 808/2017}

O dano extrapatrimonial é gênero, do que as espécies são o dano moral, o dano estético e o dano existencial.

A respeito da denominação utilizada, contra ela faz carga Oliveira (2018, p. 328-329), pois, para esse autor, em que pese seja a expressão dano extrapatrimonial terminologicamente correta, melhor teria sido utilizar a expressão dano moral, que “já consolidou raízes profundas na cultura jurídica brasileira, tanto na lei como na jurisprudência”, servindo o que entende ser uma renomeação, possivelmente, para este autor, de fonte de confusão, talvez até legitimando um dano moral mitigado em questões trabalhistas.

De qualquer sorte, ressalta-se que será analisado, neste texto, estritamente o dano moral, tendo em vista que o art. 223-B delimita a ele e ao dano existencial a tarifação:

Art. 223-B Causa dano de natureza extrapatrimonial a ação ou omissão que ofenda a esfera moral ou existencial da pessoa física ou jurídica, as quais são as titulares exclusivas do direito à reparação.

Desse modo, a redação do artigo aponta que há dano extrapatrimonial quando ocorre uma ação ou omissão capaz de causar dano moral ou existencial ao trabalhador ou ao empregador, cabendo-lhe o direito de reparação (OLIVEIRA, 2017, p. 340).

O caput do art. 223-G da CLT, inserido pela reforma trabalhista, informa os requisitos que devem ser analisados pelo juiz do trabalho para definir a gravidade do dano pleiteado:

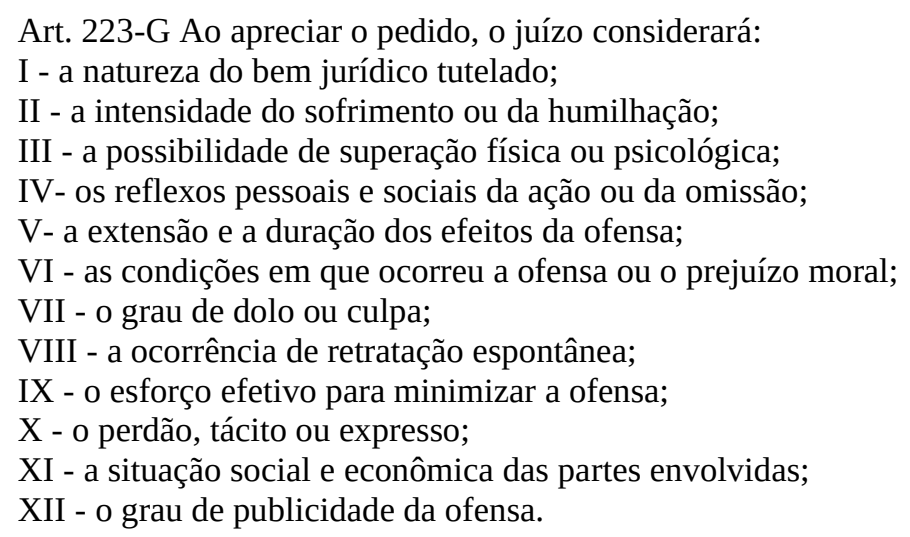

Observados esses critérios, o juiz aplicará o § 1 do artigo, fixando se o dano moral sofrido pelo obreiro é de natureza leve, média, grave ou gravíssima. Dependendo da decisão anterior, a liquidação do dano moral será ajustada conforme os cálculos editados pelo legislador: 
$\S 1^{\circ}$ Se julgar procedente o pedido, o juízo fixará a indenização a ser paga, a cada um dos ofendidos, em um dos seguintes parâmetros, vedada a acumulação:

I- ofensa de natureza leve, até três vezes o último salário contratual do ofendido;

II - ofensa de natureza média, até cinco vezes o último salário contratual do ofendido;

III - ofensa de natureza grave, até vinte vezes o último salário contratual do ofendido;

IV - ofensa de natureza gravíssima, até cinquenta vezes o último salário contratual do ofendido (BRASIL, 2017a, grifo nosso).

Em razão da delimitação do dano é possível afirmar que a reforma trabalhista trouxe consigo a tarifação - que Oliveira (2018, p. 243) entende ser mais correto denominar de tabelamento - do dano moral, pelo que, nos casos que são julgados procedentes, desde a entrada em vigor da Lei $\mathrm{n}^{0}$ 13.467, de 2017, a liquidação da lesão sofrida deve estar consoante ao quantum previsto no § 1, do art. 223-G, da CLT.

Se o dano for de natureza leve, valor máximo de três vezes o último salário do trabalhador; caso seja de natureza média e grave, cinco e 20 vezes, respectivamente, o último salário; e, por fim, constatado dano gravíssimo, 50 vezes.

As discussões acerca desse tema e de outros que envolvem a reforma trabalhista levou à edição da Medida Provisória (MP) nº 808/2017, com o objetivo claro de ajustar aspectos da reforma que foram compreendidos como pouco adequados. Segundo Henrique Correia (2018, p. 1.193), com ela surgiu a "reforma da reforma".

Como é de conhecimento geral, quando editada, a MP surtiu efeitos imediatos desde sua publicação, como é próprio deste ato normativo. Com ela, vislumbrou-se a tentativa de modificação do art. 223-G, § 1, com regras diversas da prevista na reforma.

Era este o texto:

Art. 223-G- Ao julgar procedente o pedido, o juízo fixará a reparação a ser paga, a cada um dos ofendidos, em um dos seguintes parâmetros, vedada a acumulação:

I- $\quad$ para ofensa de natureza leve - até três vezes o valor do limite máximo dos benefícios do Regime Geral de Previdência Social;

II- para ofensa de natureza média - até cinco vezes o valor do limite máximo dos benefícios do Regime Geral de Previdência Social;

III- para ofensa de natureza grave - até vinte vezes o valor do limite máximo dos benefícios do Regime Geral de Previdência Social; ou

IV- $\quad$ para ofensa de natureza gravíssima - até cinquenta vezes o valor do limite máximo dos benefícios do Regime Geral de Previdência Social. (BRASIL, 2017b, grifo nosso).

Note-se que, acima, até o presente momento, visa-se apresentar apenas a modificação do artigo que prevê a tarifação do dano moral, sem fazer juízo valorativo ou posicionamento sobre tais alterações, o que será alvo da seção seguinte.

Entre o texto da reforma trabalhista e o da Medida Provisória 808/2017 houve a mudança do parâmetro de cálculo que viabilizaria a tarifação pretendida aos lesados. Enquanto o legislador 
entendeu por bem fixar o último salário, a MP introduziu um novo coeficiente para a multiplicação e, consequentemente, um novo balizador do valor: o teto do Regime Geral de Previdência Social (RGPS).

Para melhor compreensão, o Regime Geral de Previdência Social é previsto no art. 201 da Constituição Federal e é caracterizado como contribuição obrigatória (GOES, 2018, p. 17), e sob ele recai o teto, valor máximo que recebe o beneficiário da Previdência Social. Nesse sentido, independentemente do ofício desempenhado pelo trabalhador, o dano seria estipulado entre um valor mínimo e máximo sempre definido a cada ano.

Exemplificando: no ano de 2018, o valor-teto do RGPS totalizou R\$ 5.645,80, segundo o Ministério da Economia ${ }^{1}$. Logo, o maior valor que poderia ser recebido em juízo por dano moral, definido como lesão gravíssima, seria de R\$ 282.290,00, ou seja, 50 vezes o valor do teto.

A MP nº 808/2017 não teve sua vigência prolongada (vigeu de 14/11/2017 a 23/04/2018), tendo sido apreciada em definitivo pelo Congresso Nacional, o que afastou o parâmetro do teto do RGPS para a liquidação do dano moral.

Nesse contexto, voltou a vigorar o texto do art. 223-G, § 1, da CLT, como votado pelo Legislativo e sancionado pelo Presidente da República, e que adota como medida o último salário recebido pelo obreiro lesionado.

\section{A (IN)CONSTITUCIONALIDADE DA TARIFAÇÃO DO DANO MORAL}

A grande polêmica acerca da estipulação do dano moral reside na impossibilidade de quantificar precisamente sua reparação. Diante dessa celeuma, o legislador visou fixar no salário do trabalhador um paradigma para que se chegue ao que se entende mais aproximado do dano a ele ocasionado. A ideia, claramente, era dar objetividade à questão, permitindo ao julgador uma atuação com aparência de mais segurança.

Em uma primeira análise, a estipulação criada pelo legislador parece aceitável diante da imprecisão da quantificação de um dano intangível materialmente. O íntimo lesionado parece uma escuridão sem fim para individualizar a quantia mais justa. Assim, a priori, o paradigma de adotar o último salário aparenta ser viável, até para evitar indenizações muito aquém do razoável, ou, de outra banda, excessivas.

1 Disponível em: https://bit.ly/35tumAL. 
No entanto, cumpre destacar que o texto do art. 223-G, § 1, sofreu severas críticas quanto à sua aplicabilidade prática e no seu intuito de reparar devidamente o indivíduo lesionado. Isso porque se questiona se é de fato a maneira mais justa de reparação de danos morais.

Destaca-se que a análise da tarifação do dano extrapatrimonial neste texto se dará sobre dois prismas: primeiro, quanto aos multiplicadores inseridos pela reforma; segundo, quanto o parâmetro de cálculo salarial.

Nesse sentido, quanto ao primeiro aspecto, o argumento inicialmente levantado contra o dispositivo é de que a tarifação do dano moral devida ao trabalhador é subjetiva, característica que advém do próprio instituto e que, portanto, a estipulação do legislador inobserva a delimitação do dano pelo princípio da proporção no caso concreto, taxando um multiplicador ao que julga ser considerado dano “leve”, “mediano”, “grave” e “gravíssimo” e impedindo, assim, a reparação integral do dano.

Segundo Leite (2017, p. 63),

O novo art. 223-G da CLT revela a intenção do legislador ao impor verdadeira capitis diminutio na competência dos magistrados do trabalho em fixar o valor dos danos morais. Além disso, o dispositivo em causa é flagrantemente inconstitucional, porquanto a fixação do dano moral é tipicamente um julgamento por equidade e com equidade, ou seja, o magistrado deve adotar a técnica da ponderação com base nos princípios da razoabilidade e da proporcionalidade. Nesse sentido, aliás, o STF afastou do ordenamento jurídico brasileiro a possibilidade de "tarifação" legal do dano moral (ADPF 130/DF), tal como estava previsto na chamada Lei de Imprensa (que, segundo o STF, não foi recepcionada pela CF), sob o fundamento de que a Constituição Federal não permite que a lei possa, a priori, estabelecer o valor tarifado dos danos morais.

Henrique Correia (2018, p. 1.190-1.191), seguindo o entendimento acima, aponta que pela previsão da Súmula 281 do STJ, o dano moral não está sujeito a tarifação, com interpretação análoga devendo ser aplicada ao Direito do Trabalho. Também aduz que o Ministério Público do Trabalho argumenta ser o sistema de tarifação inconstitucional em virtude da limitação que ela ocasiona, impedindo uma reparação integral ${ }^{2}$.

É a redação da Súmula 281/ STJ: “A indenização por dano moral não está sujeita à tarifação prevista na Lei de Imprensa” (BRASIL, 2004).

No mesmo sentido, discorre Delgado (2017, p. 706):

Registre-se que a quantia indenizatória por dano moral, mesmo o derivado de lesão à saúde do trabalhador, não tem como ser fixada com a objetividade inerente à indenização por danos materiais. Prevalecerá, em tais casos, inegável juízo de equidade pelo julgador.

2 Nesse aspecto, da reparação integral, talvez se devesse questionar como poderia ser ela mensurada, dada a natural subjetividade que envolve o dano extrapatrimonial. 
Nesse sentido, os autores entendem que o dano nem mesmo poderia ser tarifado por multiplicadores. No entanto, não é o que aqui se defende.

A estipulação de um coeficiente multiplicador é vantajosa no sentido de evitar que os juízes do trabalho quantifiquem valores elevadíssimos que, em muitos casos, são arbitrados desassociados à capacidade econômica do empregador - que deve ser observado segundo o inciso XI, do art. 223G, da CLT -, com pouca efetividade prática, visto que o trabalhador não receberá tais valores, caso abusivos e excedendo à capacidade do empregador de com eles arcar.

Nesse entendimento se encontra o posicionamento de Enoque Ribeiro dos Santos, desembargador no TRT da $1^{\text {a }}$ Região, quando disciplina que:

Embora o Superior Tribunal de Justiça, pela Súmula no 281 tenha fixado o entendimento no sentido de que: "A indenização por dano moral não está sujeita a tarifação prevista na Lei de Imprensa", cremos que o estabelecimento de critérios objetivos, como ora proposto pela Lei da Reforma Trabalhista (Lei n. 13.467/2017) promoverá uma parametrização do valor da reparação aos magistrados e aplicadores do direito, bem como uma maior previsibilidade e segurança jurídica aos atores sociais (SANTOS, 2017, p. 68).

Nesse diapasão, com respeito aos doutrinadores que se opõem à tarifação em geral, defendese aqui que a delimitação de dano leve, médio, grave e gravíssimo com os multiplicadores máximos de três, cinco, 20 e 50 são salutares e direcionam a discricionariedade do juiz, a ponto de coibir a fixação de condenações desarrazoadas e incompatíveis com a realidade dos casos concretos, além de objetivar que o exercício jurisdicional não seja tão destoante em casos semelhantes.

Ademais, observa-se que a utilização dessas quantias não retira a necessidade de avaliação pelo juiz no caso concreto. O magistrado continua com sua subjetividade quanto ao valor que entende necessário a reparar o dano moral do trabalhador, apenas devendo observar os limites a ele impostos pelo legislador, estando dentro dessa margem apto a quantificar quanto julgar justo para a devida lesão.

É importante observar, ainda, que, nesse caso, para que ficasse patente a inconstitucionalidade seria necessário indicar, concretamente, um direito fundamental violado em razão da parametrização, transformando a questão, como afirma Dworkin (2011), em uma questão insensível à escolha. Não é o caso, pois, não há proibição no texto constitucional de que isso ocorra, nem indicação de uma solução diversa.

A questão podia, então, ser objeto de deliberação pelo legislador infraconstitucional, como de fato o foi, estando dentro da competência do Congresso Nacional decidir sobre a matéria.

Poder-se-ia até questionar que não foi a melhor opção, dizendo que, como parametrizado, o valor poderá ficar, em certos casos, aquém do devido. Isso, todavia, não gera a inconstitucionalidade, 
devendo ser resolvido por alteração legislativa, ou seja, por uma ação que ocorra dentro do Poder Legislativo, não pela via da revisão judicial.

Nesse sentido, alegar, como fazem Melo Filho e Calábria (2017, p. 348-354), que há retrocesso social e violação da dignidade, não faz sentido sob o aspecto da constitucionalidade. No primeiro caso porque só caberia falar em retrocesso capaz de impedir a validade das disposições se fosse apontado um dispositivo constitucional que sustentasse de forma direta essa ideia de retrocesso, o que não é o caso. E, no segundo, porque a dignidade é o fundamento dos direitos fundamentais, não podendo ser invocada diretamente como violada, mas sim que é ferida porque determinado direito ou garantia foi atingido, o que, novamente, não é o caso.

Alegações de injustiça da norma precisam ser sustentadas na violação clara de um direito básico das pessoas, não em um juízo puramente valorativo. É que, entender que se pode afastar uma norma somente porque ela discrepa de nosso juízo a respeito de como os direitos devem ser distribuídos entre os integrantes da sociedade - o que se denomina de justiça distributiva - é, claramente, desrespeitar uma das bases da ideia de democracia, que é a de que a maioria formada dentro de um processo político igualitário de escolha dos representantes pode decidir como as relações na sociedade serão regidas, desde que em relação às questões sensíveis à escolha do parlamento, sendo a outra, aqui discutindo a questão de forma sucinta, o respeito aos direitos básicos dos cidadãos, com destaque evidente, aqui, para os direitos fundamentais.

Nesse sentido, ou seja, da existência e convivência dessas bases:

Isso parece natural para todos os que acreditamos que a regra da maioria é importante para a
noção de democracia, mas não se pode sobrepor ao respeito a valores previamente definidos
pela comunidade, e que devem ser preservados da vontade de uma maioria circunstancial,
qualquer que ela seja, salvo quando existe a possibilidade de alteração desses valores, de
forma também previamente definida (BRITO FILHO; FREITAS, 2017, p. 69-70).

No entanto, há de se ressaltar que a tarifação não é, em seu todo, justa, o que leva à verificação da tarifação em seu segundo aspecto. Ao passo que a fixação de números multiplicadores condiz com o bom senso na fixação do dano ocasionado, do contrário, estabelecer como parâmetro o último salário do contrato do empregado emana injustiça sem tamanho.

Embora alguns defendam que a fixação pelo salário individualiza o ajuste do valor do dano, na prática implica tratamento desigual entre os trabalhadores. O melhor exemplo para compreender a disparidade é observando a fixação na seguinte situação: imaginem-se duas trabalhadoras que laboram no mesmo ambiente - uma secretária que recebe salário equivalente a duas vezes o salário mínimo e uma faxineira que recebe o mínimo. Se ambas sofrerem assédio moral, sendo ridicularizadas por seu chefe, e ambas desejarem ajuizar ação na Justiça do Trabalho pleiteando danos 
morais advindos do tratamento constrangedor que receberam, apesar de serem humilhadas pelos mesmos motivos, a secretária, por ter maior salário, receberá, por via de consequência, indenização superior à devida à faxineira, simplesmente pelo fato de estar em um cargo superior a ela. Se os constrangimentos são iguais, por que a secretária tem direito a obter valor superior ao da faxineira?

Henrique Correia (2018, p. 1.191) expõe outro exemplo: imagine-se que, em um mesmo evento, faleçam, em razão de acidente de trabalho em obra, um pedreiro que recebe $\mathrm{R} \$ 1.000,00$ e um engenheiro com salário de R\$ 5.000,00. Com as modificações na CLT, o valor máximo que pode ser recebido a título de danos morais pela família do pedreiro é R\$ 50.000,00, e pela família do engenheiro, $\mathrm{R} \$ 250.000,00$. A vida do engenheiro teria mais valor que a do pedreiro? Qual a relação entre o dano e o salário? Como afirmar que o dano a quem recebe mais é superior ao de quem recebe menos?

A situação é ainda mais problemática quando os trabalhadores ingressam na Justiça do Trabalho em litisconsórcio ativo - no caso de o dano decorrer do mesmo fato. Isso porque o trabalho do juiz será mais árduo ao equilibrar os valores a serem recebidos, pois o parâmetro salarial é diverso. Além disso, também encontrará dificuldade a atuação do advogado, pois, como ele explicará ao seu cliente que, embora com lesões oriundas do mesmo acontecimento, o valor percebido será inferior ao do trabalhador que recebe mais? (CARNEIRO, 2017, p. 4).

O mesmo é defendido por Leite (2017, p. 63-64), que leciona que:

De outro giro, o art. 223-G, criado pela Lei 13.467/2017, estabelece odiosa discriminação entre os trabalhadores pelos salários percebidos no tocante aos valores que devem ser fixados a título de danos morais, o que também revela a sua inconstitucionalidade por violação ao princípio da igualdade, inexistindo qualquer justificativa movida pelo interesse público para tal discriminação.

Não há lógica na estipulação pelo salário, pois, esse parâmetro apenas aumenta a desigualdade entre os que possuem melhores condições e os menos favorecidos, distanciando o instituto de uma equiparação entre os trabalhadores. Destarte, a opção pela remuneração não se demonstra constitucional, violando o princípio da igualdade e afrontando a isonomia de que "todos são iguais perante a lei, sem distinção de qualquer natureza”, prevista no Art. $5^{\circ}$ da Constituição Federal (BRASIL, 1988).

Nesse diapasão, questões semelhantes são tratadas com desproporcionalidade, ferindo a igualdade entre os trabalhadores, os quais não podem ser estigmatizados, em danos personalíssimos, por seus salários, o que levaria a privilegiar os que possuem cargos mais bem remunerados com indenizações que os mais mal remunerados não obteriam nem com a violação de dano moral 
gravíssima, pois a função ou a atribuição do trabalhador não é relacionável à possibilidade de reparar seu dano.

Nesse cenário, o atual texto é inconstitucional, por prever estipulação por salário, sendo, além disso, insatisfatória a indenização daí decorrente, por diferenciar sem fundamento plausível os obreiros.

Com o parâmetro de cálculo pelo salário, chega-se à conclusão de que o legislador entendeu que:

[...] embora os trabalhadores sejam merecedores de igual tratamento digno, eles devem ser separados de acordo com seus salários, para fins de mensuração de seu patrimônio moral. Quanto menor o salário, menor será a reparação da dignidade do trabalhador. Ou, em outras palavras, a dignidade e o patrimônio moral do trabalhador são proporcionais ao seu valor no mercado de trabalho (CASAGRANDE, 2017, p. 68).

Diante dessa distorção, qual seria o melhor meio de equiparação sem vincular o cálculo ao salário dos trabalhadores e, ao mesmo tempo, manter as proporções numéricas para a multiplicação criada pelo legislador?

Acredita-se que a melhor alternativa foi a adotada, temporariamente, pela Medida Provisória $n^{\circ} 808 / 2017$.

Como abordado no tópico anterior, a MP 808/2017 alterava o art. 223-G da CLT no que toca ao parâmetro de cálculo, excluindo o salário para adotar o teto do Regime Geral de Previdência Social, tornando-se satisfatória na reparação do dano moral.

Utilizar o teto na computação do dano moral afastaria a desigualdade criticada no presente texto, observada como ponto negativo na tarifação do dano moral na reforma trabalhista.

Sendo assim, esse posicionamento seria o ideal a ser adotado pelo Supremo Tribunal Federal ao analisar a inconstitucionalidade do artigo 223-G, § 1, da CLT, pautando seus argumentos no princípio da igualdade dos trabalhadores, de forma a tornar a estipulação do dano moral impessoal, sendo estabelecido unicamente em razão do dano sofrido pelo trabalhador, e ainda que isso exija tornar sem efeito o dispositivo, impondo uma nova atuação legislativa.

Há quem defenda ainda que o importe do dano moral realizado sobre o teto do RGPS mantinha - e manteria, caso novamente utilizado - a inconstitucionalidade do Art. 223-G, § 1. Foi o que a Associação Nacional dos Magistrados da Justiça do Trabalho (Anamatra) argumentou ao ajuizar Ação Direita de Inconstitucionalidade (ADI 5870) no Supremo Tribunal Federal, requerendo, liminarmente, a suspensão dos incisos I a IV e do $\S 1$ do artigo 223-G da CLT, estabelecidos pela 
reforma, e no mérito pleiteou a procedência da ação para declarar a inconstitucionalidade desses dispositivos. O relator do caso é o ministro Gilmar Mendes ${ }^{3}$.

Os fundamentos da Anamatra perpassam pela impossibilidade de se fixar uma indenização superior à efetivamente devida ao obreiro pela tarifação incorporada pela reforma trabalhista. Acrescentou, também sobre o texto da MP 808/2017, que por mais que ele afastasse a violação do princípio da isonomia, ainda assim inviabilizava uma indenização ampla decorrente do dano extrapatrimonial sofrido, nos moldes do art. 7, XXVIII, da Constituição Federal (BRASIL, 1988), sendo os multiplicadores uma restrição à atuação judicante e à independência dos juízes.

Ademais, por analogia, defendeu que, quando o STJ firmou jurisprudência quanto à não tarifação do dano moral na Lei de Imprensa, a tarifação da indenização por dano moral decorrente da relação de trabalho também seria inconstitucional, por interpretação extensiva.

Ou seja, para a Anamatra, mesmo que houvesse vigorado a redação da MP, permaneceria a inconstitucionalidade do dispositivo. No entanto, esse não é o melhor entendimento, defende-se, porque, entre uma estipulação desigual pelo salário e o antigo arbitramento livre pelo magistrado, o meio-termo se encontra justamente na aferição pelo teto do RGPS.

Portanto, observa-se que o art. 223-G, § 1 não é em seu todo incompatível com a ideia de estabelecer as condições para a fixação do dano moral, pois, de um lado há a tentativa de guiar os juízes na fixação do dano, e de outro busca-se evitar decisões nitidamente díspares a casos semelhantes. Ainda assim, mereceria reforma o parâmetro salarial do cálculo, sendo uma boa solução a adoção do teto do RGPS, considerando que, assim, a reparação se tornaria impessoal e garantiria o respeito ao princípio da isonomia entre os trabalhadores, conforme prescreve o texto constitucional.

Ainda que na prática muitos juízes desejem legislar, os limites dos multiplicadores foram validamente inseridos no texto da reforma na tentativa de repelir condenações astronômicas, ou até mesmo suprir a ausência de parâmetros para o que seria um caso leve, médio, grave ou gravíssimo, pois a realidade demonstrava desigualdade nas decisões judiciais. Por outro lado, é necessário um parâmetro fixo, e não por meio do salário, a fim de que se possam criar critérios mais justos, com condenações mais similares em situações semelhantes.

Por fim, há o argumento de que os valores estabelecidos no art. 223-G, § 1 deveriam servir apenas de parâmetro para o julgamento dos juízes, sem que haja seu emprego obrigatoriamente. Contra esse argumento insurge a ineficácia do próprio instituto de tarifar o dano moral. Se o artigo fosse apenas para ajudar na interpretação do magistrado, sem aplicação vinculada, de nada adiantaria

3 Disponível em: https://bit.ly/2QOuqG1. 
sua previsão, porque seu objetivo é, exatamente, evitar condenações abusivas e permitir que o dano seja estipulado de forma mais justa. Se fosse de uso facultativo, estaria expresso em seu texto “poderá”, mas, não é o que se constata, pois se encontra a expressão “fixará”, devendo, portanto, o magistrado aplicá-lo sempre.

\section{CONCLUSÃO}

A Lei 13.467/17, intitulada de reforma trabalhista, trouxe consigo diversas alterações no mundo do trabalho. Não se deve analisar, de forma generalizada, se essas modificações foram vantajosas ou maléficas aos trabalhadores, de forma que precisam de análise pontual sobre cada um dos temas, porque toda reforma tem pontos negativos e positivos.

Neste texto abordou-se a inserção do artigo 223-G, § 1, da CLT, que inovou quanto à possibilidade de tarifação do dano extrapatrimonial.

Como visto, o dano moral, diferentemente do dano material, não é objetivo; ao contrário, depende da subjetividade, pois afeta bem personalíssimo, como a honra e a imagem, não pecuniários. Esse instituto surgiu no Direito Civil e foi incorporado pelo Direito do Trabalho no escopo de reparar, no meio ambiente laboral, danos à personalidade.

No que se refere ao dano moral na Justiça do Trabalho, o presente texto entendeu que o artigo 223-G, § 1, da CLT não é de todo inconstitucional, uma vez que a prescrição legislativa, ao inserir multiplicadores fixos para o cálculo, visa reduzir condenações vultosas, pelos magistrados, que desconsiderem a condição econômica das partes, prevista no inciso XI, do art. 223-G, e ainda contribuindo para orientar a decisão do juiz do trabalho no cálculo da condenação, posicionamento não seguido por doutrinadores como Maurício Godinho Delgado (2017), Carlos Henrique Bezerra Leite (2017) e Henrique Correia (2018).

No entanto, a pesquisa ressaltou que, no que toca ao parâmetro de fixação, qual seja, o salário do trabalhador, o artigo necessita de reforma. Apesar de alguns doutrinadores entenderem que a estipulação do dano extrapatrimonial tendo como base de cálculo o último salário do obreiro individualiza a condenação, tal estipulação na prática abre espaço para a violação do princípio da igualdade, previsto no art. $5^{\circ}$ da Constituição Federal, sendo assim inconstitucional nessa parte e, consequentemente, é insatisfatória para a devida reparação do dano moral pleiteado pelos obreiros.

Isso se dá em razão do tratamento distinto para aqueles que possuem melhor remuneração, permitindo que a reparação do dano extrapatrimonial se afaste da devida restituição da dignidade e do abalo ao direito de personalidade, tornando-se alvo de cálculos definidos pelo valor de mercado 
dos trabalhadores lesionados, aferindo “maior dignidade” aos que recebem maiores salários e menores valores de condenação aos que possuem menores remunerações, mesmo em contextos iguais de violação de direitos.

Note-se que, como indicado ao final da seção 2, no caso de dano extrapatrimonial não é possível trabalhar com a certeza de reparação integral, dada a aludida subjetividade. Isso exige trabalhar com uma ideia de padrão médio que, contudo, não se deveria vincular a cada trabalhador, mas, à gravidade da lesão, independentemente do salário de cada obreiro.

Como a declaração da inconstitucionalidade, todavia, não poderá ter o condão de mudar o parâmetro de cálculo da indenização, fazendo voltar o que foi definido pela MP 808, mas, tão somente afastar a incidência do dispositivo, o melhor seria que, ao lado dessa declaração, e até à revelia dela, o Congresso Nacional fizesse voltar o parâmetro que toma por base o teto dos benefícios do RGPS, como acima foi defendido.

Em resumo, foi defendido no presente trabalho que a melhor alternativa seria a mudança do atual texto, por aquele presente na não mais vigente Medida Provisória nº 808/2017, tendo em vista que ela mantinha os multiplicadores úteis estabelecidos pelo legislador e, de modo simultâneo, preservava a isonomia de tratamento, adotando um parâmetro impessoal aplicável indistintamente a todos os trabalhadores.

\section{REFERÊNCIAS}

BRASIL. Constituição da República Federativa do Brasil de 1988. Diário Oficial da União, Brasília, DF, 5 de outubro de 1988. Disponível em: http://bit.ly/2LCVeqG. Acesso em: 1 mar. 2019.

BRASIL. Decreto-Lei ${ }^{\circ}$ 5.452, de $1^{\circ}$ de maio de 1943. Aprova a Consolidação das Leis do Trabalho (com a Reforma Trabalhista da Lei 13.467/2017). Diário Oficial da União, Rio de Janeiro, 1 de maio de 1943. Disponível em: http://bit.ly/2LD1u1Q. Acesso em: 1 mar. 2019.

BRASIL. Lei $n^{\circ}$ 13.467, de 13 de julho de 2017. Altera a Consolidação das Leis do Trabalho (CLT), aprovada pelo Decreto-Lei $n^{\circ} 5.452$, de $1^{\circ}$ de maio de 1943 , e as Leis $n^{\circ} 6.019$, de 3 de janeiro de 1974, 8.036, de 11 de maio de 1990, e 8.212, de 24 de julho de 1991, a fim de adequar a legislação às novas relações de trabalho. Diário Oficial da União, Brasília, DF, 14 de julho de 2017a. Disponível em: https://bit.ly/2STOJEC. Acesso em: 1 mar. 2019.

BRASIL. Medida Provisória nº 808, de 14 de novembro de 2017. Altera a Consolidação das Leis do Trabalho - CLT, aprovada pelo Decreto-Lei ${ }^{\circ}$ 5.452, de $1^{\circ}$ de maio de 1943 . Diário Oficial da União, Brasília, DF, 14 de novembro de 2017b (edição extra). Disponível em: http://bit.ly/2rt39jy. Acesso em: 29 mar. 2019. 
BRASIL. Superior Tribunal de Justiça. Súmula 281. A indenização por dano moral não está sujeita à tarifação prevista na Lei de Imprensa. Segunda Seção, julgado em 28/04/2004, DJe, 13/05/2004, p. 200. Disponível em: https://bit.ly/2N0G2Va. Acesso em: 2 maio 2019.

BRITO FILHO, José Claudio Monteiro de; FREITAS, Juliana Rodrigues. Revisão judicial de questões insensíveis à escolha em matéria política: o caso da ADI 5632 e dos mandados de segurança 34.574, 34.599 e 34.602. In: BARBOSA, Claudia Maria Barbosa et al. Acesso à justiça. Florianópolis: CONPEDI, 2017.

CARNEIRO, Fabricio Segato. A (in)constitucionalidade da tarifação do dano extrapatrimonial. Consultor Jurídico, 5 ago. 2017. Disponível em: http://bit.ly/2P2ML2n. Acesso em: 1 maio 2019.

CASAGRANDE, Cássio. A reforma trabalhista e a inconstitucionalidade da tarifação do dano moral com base no salário do empregado. Revista Jurídica da Escola Superior de Advocacia da OAB-PR, ano 2, núm. 3, dez. 2017. Disponível em: http://bit.ly/36npQ7P. Acesso em: 1 mar. 2019.

CORREIA, Henrique. Direito do trabalho para concursos de analista do TRT, TST e MPU. 12. ed. Salvador: Editora JusPodivm, 2018.

DELGADO, Maurício Godinho. Curso do Direito do Trabalho. 16. ed. São Paulo: LTr, 2017.

DWORKIN, Ronald. A virtude soberana: a teoria e a prática da igualdade. Tradução Jussara Simões. 2. ed. São Paulo: Editora WMF Martins Fontes, 2011.

FERRARI, Irany; MARTINS, Melchíades Rodrigues. Dano moral: múltiplos aspectos nas relações de trabalho. São Paulo: LTr, 2005.

GAGLIANO, Pablo Stolze; PAMPLONA FILHO, Rodolfo. Novo curso de direito civil. Vol. 3. 11. ed. São Paulo: Saraiva, 2013.

GOES, Hugo. Manual de direito previdenciário: teoria e questões. 14. ed. Rio de Janeiro: Editora Ferreira, 2018.

LEITE, Carlos Henrique Bezerra. Curso de direito do trabalho. 8. ed. São Paulo: Saraiva, 2017.

MELO FILHO, Hugo Cavalcante; CALÁBRIA, Renata Alves. Do arbitramento do dano extrapatrimonial: inconstitucionalidade do $\S 1^{\circ}$ do artigo 223-G da CLT, introduzido pela Lei $n$. 13.467/17. In: MELO, Raimundo Simão de; ROCHA, Cláudio Jannotti (coord.).

Constitucionalismo, trabalho, seguridade social e a reformas trabalhista e previdenciária. São Paulo: LTr, 2017.

OLIVEIRA, Sebastião Geraldo de. O dano extrapatrimonial trabalhista após a Lei N. 13.467/2017, modificada pela MP N. 808, de 14 de novembro de 2017. Revista do Tribunal Regional do Trabalho da $3^{\text {a }}$ Região, Belo Horizonte, edição especial, p. 333-368, nov. 2017. Disponível em: http://bit.ly/36lxf7k. Acesso em: 1 maio 2019. 
OLIVEIRA, Sebastião Geraldo de. O dano extrapatrimonial trabalhista após a Lei n. 13.467/2017. In: MARTINEZ, Luciano et al. (org.). A reforma trabalhista na visão da Academia Brasileira de Direito do Trabalho. Porto Alegre: LexMagister, 2018.

PEREIRA, Caio Mário da Silva. Responsabilidade Civil. 12. ed. Atualizador: Gustavo Tepedino. Rio de Janeiro: Forense, 2018.

SANTOS, Enoque Ribeiro dos. O dano extrapatrimonial na Lei n. 13.467/2007, da reforma trabalhista. Revista eletrônica do Tribunal Regional do Trabalho da $9^{a}$ Região, Curitiba/PR, v. 7, n. 62, p. 62-69, set./out. 2017. Disponível em: http://bit.ly/2P3kRmM. Acesso em: 1 mar. 2019.

José Claudio Monteiro de Brito Filho Doutor em Direito das Relações Sociais pela PUC-SP, professor no PPGD e no Curso de Graduação do Centro Universitário do Estado do Pará, titular da Cadeira no 26 da Academia Brasileira de Direito do Trabalho.E-mail: jclaudiobritofilho@gmail.com

Sarah Gabay Pereira

Estudante da graduação do curso de Direito do Centro Universitário do Estado do Pará. Email: sarahgabaypereira@gmail.com 